\title{
Enhanced neutrophil response in chronic obstructive pulmonary disease
}

\author{
A Noguera, S Batle, C Miralles, J Iglesias, X Busquets, W MacNee, A G N Agustí
}

\begin{abstract}
Background-Neutrophils are likely to play a major role in the inflammatory response seen in chronic obstructive pulmonary disease (COPD). This study sought to address the hypothesis that an enhanced neutrophil response to proinflammatory agents in COPD may contribute to their recruitment and activation in the lungs.

Methods-Circulating neutrophils were obtained from 10 patients with COPD, eight long term smokers with normal lung function, and eight healthy never smoking controls. The in vitro production of reactive oxygen species (ROS) was measured by the NADPH oxidase method (respiratory burst) and the surface expression of several adhesion molecules (Mac-1, LFA-1 and L-selectin) was measured by flow cytometry. Measurements were obtained under basal conditions and after stimulation with phorbol myristate acetate (PMA) and tumour necrosis factor alpha (TNF $\alpha)$. mRNA levels of p22-phox (a subunit of NADPH oxidase) and Mac-1 (CD11b) were also determined by reverse transcriptase polymerase chain reaction (RT-PCR).
\end{abstract}

Results-Patients with COPD showed en-

Serveis de Analisis
Cliniques, Pneumologia, and Immunologia, and Unidad de

Investigación, Hospital

Universitari Son

Dureta, Palma de

Mallorca, Spain

A Noguera

S Batle

C Miralles

$\mathrm{J}$ Iglesias

$\mathrm{X}$ Busquets

A G N Agustí

Respiratory Medicine Unit, Department of Clinical and

Radiological Science,

University of

Edinburgh, Royal

Infirmary, Edinburgh,

UK

W MacNee

Correspondence to: Dr A G N Agustí aagusti@hsd.es

Received 24 March 2000 Returned to authors 15 September 2000 Revised version received

8 November 2000

Accepted for publication

24 January 2001 smokers with normal lung function, both under basal conditions (mean (SE) fluorescence intensity (MFI) $15.1(0.5) v 11.6$ (0.5); mean difference -3.4 (95\% CI of the difference -5.1 to -1.8$), p<0.01)$ and after PMA stimulation (MFI 210 (7) $v 133$ (10); mean difference -77 (95\% $\mathrm{CI}$ of the difference -102 to -52$), p<0.01)$. Mac-1 surface expression was also enhanced in patients with COPD, both under basal conditions (MFI 91 (5) $v 45$ (3); mean difference -46 (95\% CI of the difference -61 to -31$)$, p<0.001) and after stimulation with TNFa (MFI 340 (15) $v 263$ (11); mean difference $-77(95 \%$ CI of the difference -119 to -34$)$, $\mathbf{p}=0.001)$. These differences were also apparent when patients with COPD were compared with non-smokers $(\mathrm{p}<0.05)$. The mRNA levels of p22-phox and Mac-1 (CD11b) were similar in patients with COPD and smokers with normal lung function, suggesting that the observed differences were due to post-transcriptional regulation.

Conclusions-These results demonstrate an enhanced neutrophil response to proinflammatory agents in patients with COPD which may contribute to their hanced respiratory burst compared with enhanced recruitment and activation in the lungs of these patients. These findings support those of other studies which have indicated that the neutrophil is likely to play a major role in the pathogenesis of this disease.

(Thorax 2001;56:432-437)

Keywords: chronic obstructive pulmonary disease; neutrophils; adhesion molecules; respiratory burst

Chronic obstructive pulmonary disease (COPD) is characterised by an excessive inflammatory response to (largely) tobacco smoking, ${ }^{1}$ yet only a fraction of smokers will develop the disease. ${ }^{2}$ The mechanisms underlying this observation are unknown. ${ }^{3}$

Neutrophils are key cells in the inflammatory response that characterises COPD. ${ }^{4}$ Compared with healthy non-smokers, neutrophils in patients with COPD are present in increased numbers, both in sputum and bronchoalveolar lavage fluid, ${ }^{5}$ exhibit increased chemotactic response and a greater ability to digest connective tissue ${ }^{6}$ and show enhanced surface expression of some adhesion molecules. ${ }^{7}$ Collectively, these observations indicate abnormal neutrophil function in COPD. However, whether this abnormal function represents an intrinsic neutrophil defect that favours the development of COPD or, alternatively, it reflects a state of activation (priming) of these cells due to the disease itself or to tobacco smoking (its main risk factor) is currently unknown.

To investigate these possibilities we studied neutrophil function in three groups of well characterised individuals: (1) patients with COPD; (2) long term smokers (with the same smoking history as the patients with COPD) with normal lung function; and (3) healthy, never smoking, volunteers. In these individuals we determined the production of reactive oxygen species (ROS) by NADPH oxidase (respiratory burst) and the surface expression of several adhesion molecules (Mac-1, LFA-1 and L-selectin). In order to gain insight into the potential genetic mechanisms that regulate the respiratory burst and the expression of adhesion molecules in these cells, we assessed mRNA levels of Mac-1 and the subunit p22-phox of NADPH oxidase.

\section{Methods}

SUBJECTS

Ten patients with COPD, eight long term smokers with normal lung function, and eight healthy non-smoking volunteers participated in the study. All were men of a similar age (mean (SD) 67 (2) years, 61 (2) years, and 57 (3) 
years, respectively, $\mathrm{p}>0.05)$. Patients with COPD had moderate airflow obstruction (forced expiratory volume in one second $\left(\mathrm{FEV}_{1}\right) 46.8$ (4.2)\% predicted value) and mild arterial hypoxaemia $\left(\mathrm{PaO}_{2} 9.7(0.4) \mathrm{kPa}\right)$ without hypercapnia $\left(\mathrm{PaCO}_{2} 5.3(0.2) \mathrm{kPa}\right)$. All patients were clinically stable, as defined by the absence of any change in their regular treatment and/or need to seek medical attention during the previous 4 months. Patients with bronchial asthma, pneumonia, or lung cancer were excluded. All patients were treated with inhaled bronchodilators but none received inhaled or oral steroids. None of the patients were current smokers. Their smoking history (50 (5) pack years) was similar to that of the smokers with normal lung function (53 (3) pack years). By definition, spirometric measurements were normal in the smokers without COPD $\left(\mathrm{FEV}_{1} 97.1\right.$ (5.4)\% predicted value).

All participants gave their written consent, having been fully informed of the nature, risks and potential benefits of the study. The research and ethical review committee of our institution approved the investigation.

\section{STUDY DESIGN}

Thirty $\mathrm{ml}$ of peripheral venous blood was taken from each participant. Current smokers refrained from smoking for at least 12 hours before blood sampling. ${ }^{89}$ From these blood samples neutrophils were harvested (see below) and the respiratory burst and surface expression of adhesion molecules (LFA-1, Mac-1, and L-selectin) in these neutrophils were assessed, both under basal conditions and after stimulation. In addition, in neutrophils obtained from patients with COPD and from long term smokers with normal lung function the mRNA expression of p22-phox and Mac-1 (CD11b) was examined.

LUNG FUNCTION MEASUREMENT

Forced spirometric parameters (GS Warren Collins, USA) were measured according to international guidelines. ${ }^{10}$ Spirometric reference values were those of a Mediterranean population. ${ }^{11}$ Arterial blood gas tensions (IL BG3, Izasa, Spain) were determined only in patients with COPD.

\section{ISOLATION OF NEUTROPHILS}

Neutrophils were isolated from peripheral blood samples according to the methodology previously described in our laboratory. ${ }^{7}$ Briefly, leucocyte rich plasma was obtained by mixing with an equal volume of endotoxin free Hemoce reagent (Hoechst Iberica, Barcelona, Spain). This was followed by sedimentation during 1 hour at $4^{\circ} \mathrm{C}$. Neutrophils were separated from the leucocyte rich plasma by centrifugation on a $15 \mathrm{ml}$ layer of a FicollPaque research grade gradient (Pharmacia Biotech, Uppsala, Sweden) at $900 \mathrm{~g}$ for $30 \mathrm{~min}-$ utes at $22^{\circ} \mathrm{C}$. Residual erythrocytes were removed by mixing the neutrophil rich pellet with $50 \mathrm{ml}$ of ice cold $0.15 \mathrm{M} \mathrm{NH}_{4} \mathrm{Cl}$ solution which was gently agitated at $4^{\circ} \mathrm{C}$ for 10 minutes and then centrifuged at $750 \mathrm{~g}$ for 10 minutes at $4^{\circ} \mathrm{C}$. The neutrophil pellet was washed once with phosphate buffered saline (PBS) and resuspended with $1 \mathrm{ml}$ PBS, counted by Sysmex K-4500 (Toa Medical Electronics Co Ltd) and adjusted to $4 \times 10^{6}$ cells $/ \mathrm{ml}$ with PBS. Neutrophils harvested by this technique were $>97 \%$ pure as assessed by Giemsa staining and $99 \%$ viable as assessed by trypan blue exclusion.

MEASUREMENT OF THE NEUTROPHIL RESPIRATORY BURST BY FLOW CYTOMETRY Activation of the neutrophil respiratory burst was determined by the formation of the fluorescent compound rhodamine-123 from dihydrorhodamine-123 (DHR; Molecular Probes, Eugene, OR, USA). ${ }^{12}$ In brief, two $200 \mu \mathrm{l}$ samples of the neutrophil suspension (2 $\times 10^{6}$ cells $/ \mathrm{ml}$ ) in polypropylene tubes (Falcon no 2052, Beckton-Dickinson, Lincoln Park, NJ, USA) were incubated with $10 \mu \mathrm{l}$ of a DHR solution $(100 \mu \mathrm{g} / \mathrm{ml})$ for 10 minutes at $37^{\circ} \mathrm{C}$. One sample was used to assess spontaneous ROS production. The other was mixed with $20 \mu \mathrm{l}$ of a $20 \mu \mathrm{g} / \mathrm{ml}$ phorbol myristate acetate solution (PMA; Sigma Chemical Co, St Louis, MO, USA) and incubated for 15 minutes at $37^{\circ} \mathrm{C}$. At the end of this second incubation period $500 \mu \mathrm{l}$ of cold PBS were added to both samples and these were kept on ice until analysed by flow cytometry on a BecktonDickinson FACScan (Beckton-Dickinson, Mountain View, CA, USA) with a gate setting for neutrophils on forward and side scatter. Ten thousand cells were analysed; green fluorescence (FL1) was determined and mean cellular fluorescence intensities (MFI) were calculated using LYSIS II software.

ADHESION MOLECULE IMMUNOFLUORESCENCE AND FLOW CYTOMETRIC ANALYSIS

One hundred $\mu$ l samples of neutrophil suspensions $\left(4 \times 10^{6}\right.$ cells $\left./ \mathrm{ml}\right)$ were mixed with $20 \mu \mathrm{l}$ of FITC labelled monoclonal antibody antiLFA-1 (CD11a) (25.3.1 clone, Immunotech, Marseille, France), FITC labelled anti-Mac-1 (CD11b) (BEAR 1 clone, Immunotech), FITC labelled anti-L-selectin (CD62L) (DREG56 clone, Immunotech), and FITC labelled $\mathrm{IgG}_{1}$ (2T8-2F5 MsIgG ${ }_{1}$, Coulter Immunology, Hialeah) that acted as a nonspecific control antibody. These were incubated at $4^{\circ} \mathrm{C}$ for 30 minutes, washed twice in ice cold PBS, resuspended in $1 \mathrm{ml}$ PBS, and kept on ice until analysed. Neutrophils were assessed under resting conditions and after stimulation with $2 \mathrm{ng} / \mathrm{ml}$ human tumour necrosis factor $\alpha$ (TNF $\alpha$; Sigma Chemical Co, St Louis, MO, USA) for 90 minutes at $37^{\circ} \mathrm{C}$ in $5 \% \mathrm{CO}_{2}$. Cells were assessed with a gate setting for neutrophils on forward and side scatter diagrams and fluorescence on the FL1 channel $(530 \mathrm{~nm})$ was collected with the BecktonDickinson LYsis II software. Ten thousand cell counts were accumulated for the analysis. Non-specific binding $\left(\operatorname{IgG}_{1}\right)$ on resting and stimulated neutrophils was measured at MFI values of $2.59(0.56)$ and 3.43 (0.94) units, respectively. 
RNA ISOLATION AND REVERSE

TRANSCRIPTION-POLYMERASE CHAIN REACTION

(RT-PCR)

Total RNA was extracted from the neutrophil sample using a single step isolation system (Trizol Reagent, Gibco BRL, Life Technologies, NY, USA) based on the method of Chomczynski and Sacci. ${ }^{13}$ The RNA was precipitated, washed twice with $70 \%$ ethanol, and quantified in a spectrophotometer at $260 \mathrm{~nm}$ (Shimadzu UV-Visible Recording Spectrophotometer, Shimadzu Corporation, Kyoto, Japan). Two $\mu$ g of total RNA was reverse transcripted into cDNA using the oligo $(\mathrm{dT})_{18}$ primer and AMV reverse transcriptase (Promega, Madison, WI, USA). PCR was performed on the resulting cDNA using specific primers for p22-phox (sense primer 5'-GTTTGTGTGCCTGCTGGAGT-3' and antisense primer 5'-TGGGCGGCTGCTTG ATGGT-3'), ${ }^{14}$ for CD11b (5'-CAGAGCGT GGTCCAGGCACCA-3' and 5'-CCTTCAT CCGCCGAAAGTCA-3'), ${ }^{15}$ and for $\beta$-actin (5'-GTGGGGCGCCCAGGCACCA-3' and 5'-CTCCTTAATGTCACGCACGATTTC$\left.3^{\prime}\right)^{16}$ using Taq polymerase according to the manufacturer's instructions. The PCR protocol was as follows. For p22-phox: 3 minutes at $94^{\circ} \mathrm{C}, 1$ minute at $55^{\circ} \mathrm{C}, 1$ minute at $72^{\circ} \mathrm{C}$ for one cycle; 1 minute at $94^{\circ} \mathrm{C}, 1$ minute at $55^{\circ} \mathrm{C}$, 1 minute at $72^{\circ} \mathrm{C}$ for 35 cycles; 1 minute at $94^{\circ} \mathrm{C}, 10$ minutes at $60^{\circ} \mathrm{C}$ for one cycle. For CD11b: 4 minutes at $94^{\circ} \mathrm{C}$ for one cycle; 30 seconds at $94^{\circ} \mathrm{C}, 30$ seconds at $63^{\circ} \mathrm{C}, 1$ minute at $72^{\circ} \mathrm{C}$ for 30 cycles; 5 minutes at $72^{\circ} \mathrm{C}$ for one cycle. For $\beta$-actin: 1 minute at $94^{\circ} \mathrm{C}, 1$ minute at $58^{\circ} \mathrm{C}, 2$ minutes at $72^{\circ} \mathrm{C}$ for 35 cycles; 7 minutes at $72^{\circ} \mathrm{C}$ for one cycle. Following PCR, products were fractionated by $2 \%$ agarose gel electrophoresis and stained with ethidium bromide. Gels were subjected to scanner densitometry and the bands were quantified with the aid of the Sigmagel gel analysis software (Jandel Scientific Corporation, San Rafael, CA, USA). The results are expressed as a ratio of $\beta$-actin expression, which served as a housekeeping gene.

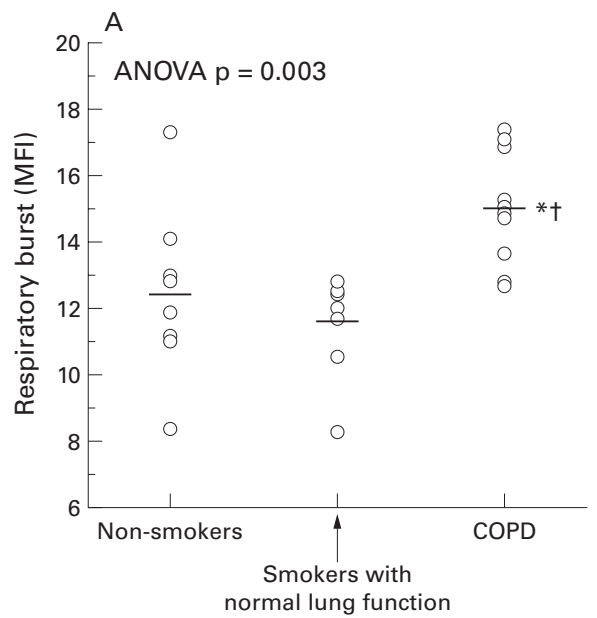

STATISTICAL ANALYSIS

The results are shown as mean (SE) together with the mean difference between groups and the $95 \%$ confidence interval (CI) of this difference. To assess the statistical significance of differences between the three study groups we used analysis of variance (ANOVA) followed by post hoc analysis (Scheffe test) if appropriate. The paired Student's $t$ test was used to investigate the significance of changes within each group after stimulation. A p value of less than 0.05 was considered significant.

\section{Results}

RESPIRATORY BURST

The production of ROS was higher in neutrophils harvested from patients with COPD (MFI 15.1 (0.5) units) than in those from smokers with normal lung function (MFI 11.6 (0.5) units; mean difference -3.4 (95\% CI -5.1 to -1.8$), \mathrm{p}<0.01$ ) or non-smokers (MFI 12.4 (0.9) units; mean difference -2.6 (95\% CI -4.8 to -0.5$)$, $\mathrm{p}=0.03$; fig 1). These differences were maintained after PMA stimulation (fig 1). The change induced by PMA on ROS production was higher in patients with COPD (MFI 195 (7) units) than in smokers with normal lung function (MFI 121 (9) units; mean difference $-73(95 \% \mathrm{CI}-98$ to -49$), \mathrm{p}<0.001)$ or in nonsmokers (MFI 133 (16) units; mean difference $-61(95 \% \mathrm{CI}-96$ to -27$), \mathrm{p}=0.001)$.

EXPRESSION OF ADHESION MOLECULES

Under basal conditions the surface expression of Mac-1 (CD11b) was higher in patients with COPD (MFI 91 (5) units) than in smokers with normal lung function (MFI 45 (3) units; mean difference -46 (95\% CI -61 to -31 ), $\mathrm{p}<0.001$ ) and non-smokers (MFI 67 (7); mean difference $-24(95 \%$ CI -39 to -10$), p=0.003$; fig 2). After stimulation with $\mathrm{TNF} \alpha$ the surface expression of Mac-1 (CD11b) was also higher in patients with COPD (MFI 340 (15) units) than in smokers with normal lung function (MFI 263 (11) units; mean difference -77 ( $95 \% \mathrm{CI}-119$ to -34 ) units, $\mathrm{p}=0.001$; fig 2 ); by contrast, there was no significant difference in

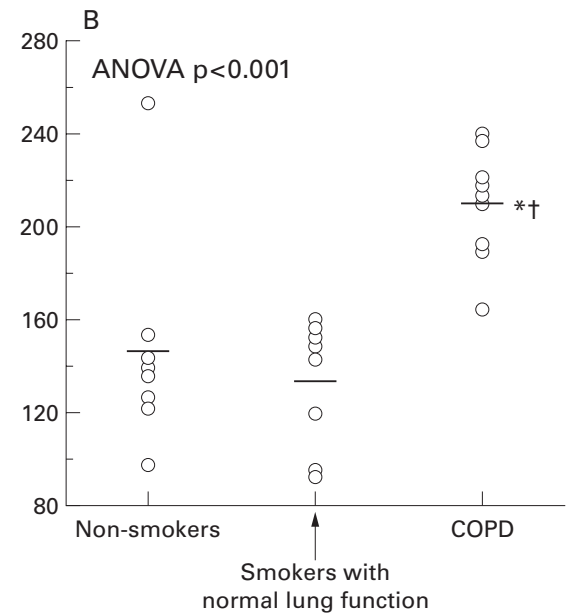

Figure 1 Scatter plots showing the DHR fluorescence (MFI, mean fluorescent intensity) of neutrophils studied (A) under basal conditions and (B) after stimulation with PMA. Each dot represents the result from one individual. Horizontal bars represent mean values. *Significant difference $v$ non-smokers; tsignificant difference $v$ smokers with normal lung function. 

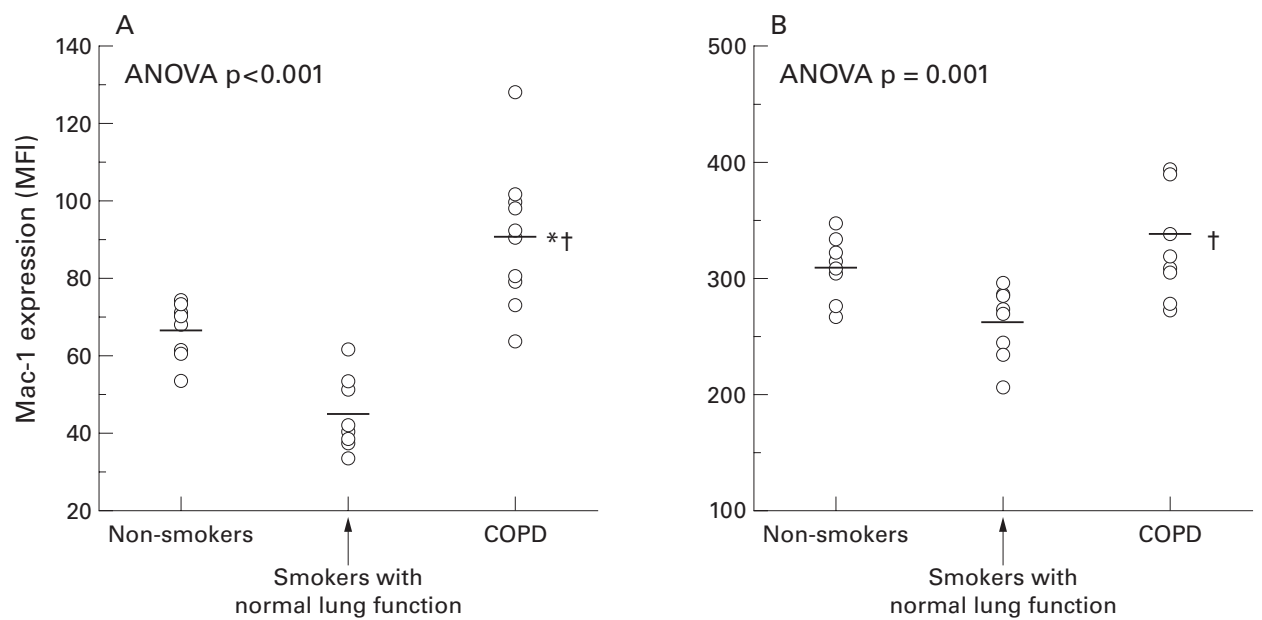

Figure 2 Scatter plots showing the surface expression of the adhesion molecule Mac-1 (CD11b) (MFI, mean fluorescent intensity) on neutrophils studied (A) under basal conditions and (B) after stimulation with TNFa. Each dot represents one determination. Horizontal bars represent mean values. ${ }^{\star}$ Significant difference $v$ non-smokers; †significant difference $v$ smokers with normal lung function.

Mac-1 expression between non-smokers (MFI 310 (9) units; mean difference -30 (95\% CI -69 to 9 )) and the other groups (fig 2). The surface expression of LFA-1 or L-selectin did not differ between the groups either under basal conditions or after stimulation with $\mathrm{TNF} \alpha$ (table 1). However, in agreement with previous studies showing that $\mathrm{TNF} \alpha$ induces the shedding of L-selectin from the neutrophil membrane, ${ }^{17}$ surface expression of L-selectin was significantly reduced after $\mathrm{TNF} \alpha$ in all groups (table 1).

GENE EXPRESSION

Figure 3A shows a representative RT-PCR result. The PCR products generated were a $316 \mathrm{bp}$ fragment for p22-phox, a $406 \mathrm{bp}$ fragment for CD11b, and a $540 \mathrm{bp}$ fragment for $\beta$-actin. Figure $3 \mathrm{~B}$ and $3 \mathrm{C}$ show the individual and average mRNA values of both Mac-1 and p22-phox in patients with COPD and smokers with normal lung function, neither of which differed significantly between the two groups.

\section{Discussion}

This study shows that circulating neutrophils harvested from patients with stable COPD produce more ROS (respiratory burst) and express more adhesion molecules (Mac-1) than those obtained from non-smokers and, importantly, from long term smokers with normal lung function. This enhanced response may be relevant for the pathogenesis of COPD.

Previous studies have shown that, compared with non-smokers, circulating neutrophils in

Table 1 Mean (SE) values of LFA-1 and L-selectin expression

\begin{tabular}{|c|c|c|c|}
\hline & $\begin{array}{l}\text { Healthy } \\
\text { non-smokers }\end{array}$ & $\begin{array}{l}\text { Smokers with } \\
\text { normal lung } \\
\text { function }\end{array}$ & $\begin{array}{l}\text { COPD } \\
\text { patients }\end{array}$ \\
\hline \multicolumn{4}{|l|}{ LFA-1 (MFI) } \\
\hline Basal conditions & (1) & (2) & (2) \\
\hline After $\mathrm{TNF} \alpha$ & (2) & (2) & (1) \\
\hline \multicolumn{4}{|l|}{ L-selectin (MFI) } \\
\hline Basal conditions & $100 \quad(6)$ & $87 \quad(5)$ & $94 \quad(9)$ \\
\hline After $\mathrm{TNF} \alpha$ & $3.2(0.2)^{\star}$ & $3.4(0.3)^{\star}$ & $3.3(0.2)^{\star}$ \\
\hline
\end{tabular}

MFI $=$ mean fluorescence intensity

${ }^{\star} \mathrm{p}<0.01$ compared with basal conditions. patients with COPD produce more ROS (enhanced respiratory burst) ${ }^{18} 19$ and express abnormal levels of some surface adhesion molecules such as Mac-1. ${ }^{7}$ Our study confirms these observations and extends them to a group of long term smokers with normal lung function. This is important because it allows us to analyse the influence of smoking and COPD independently on neutrophil function. We observed that patients with COPD showed a significant upregulation of respiratory burst and Mac-1 expression, not only with respect to non-smokers (as previously described) but also (and even more markedly) with respect to smokers with normal lung function (figs 1 and 2). Our results therefore suggest that these differences were not caused by smoking but, rather, they indicate that the abnormal neutrophil function described here is characteristic of COPD. Whether it represents a predisposing factor for COPD or is a consequence of the disease is at present unclear.

Our results highlight a potentially relevant pathogenic mechanism in COPD, such as the interaction between the respiratory burst and the expression of some (not all) surface adhesion molecules. Previous studies have established that in vitro phosphorylation of Mac-1 leads to NADPH oxidase activation ${ }^{20}$ and that cross linking of Mac-1 induces neutrophil respiratory burst. ${ }^{21}{ }^{22}$ Minamiya et $a l^{23}$ showed that neutrophil adhesion to the endothelium in rats activates the respiratory burst. Our results are in agreement with these previous experimental studies and suggest that, in patients with COPD, the enhanced expression of Mac-1 (favouring the recruitment of neutrophils to an inflammatory site) is coupled with an increased respiratory burst, augmenting their potential for lung damage. This combination of events is likely to contribute to the development of COPD.

This study also sought to gain some insight into the genetic regulation of NADPH oxidase and Mac-1 in neutrophils of patients with COPD. To this end, we determined the mRNA levels of p22-phox and Mac-1 in circulating 
A
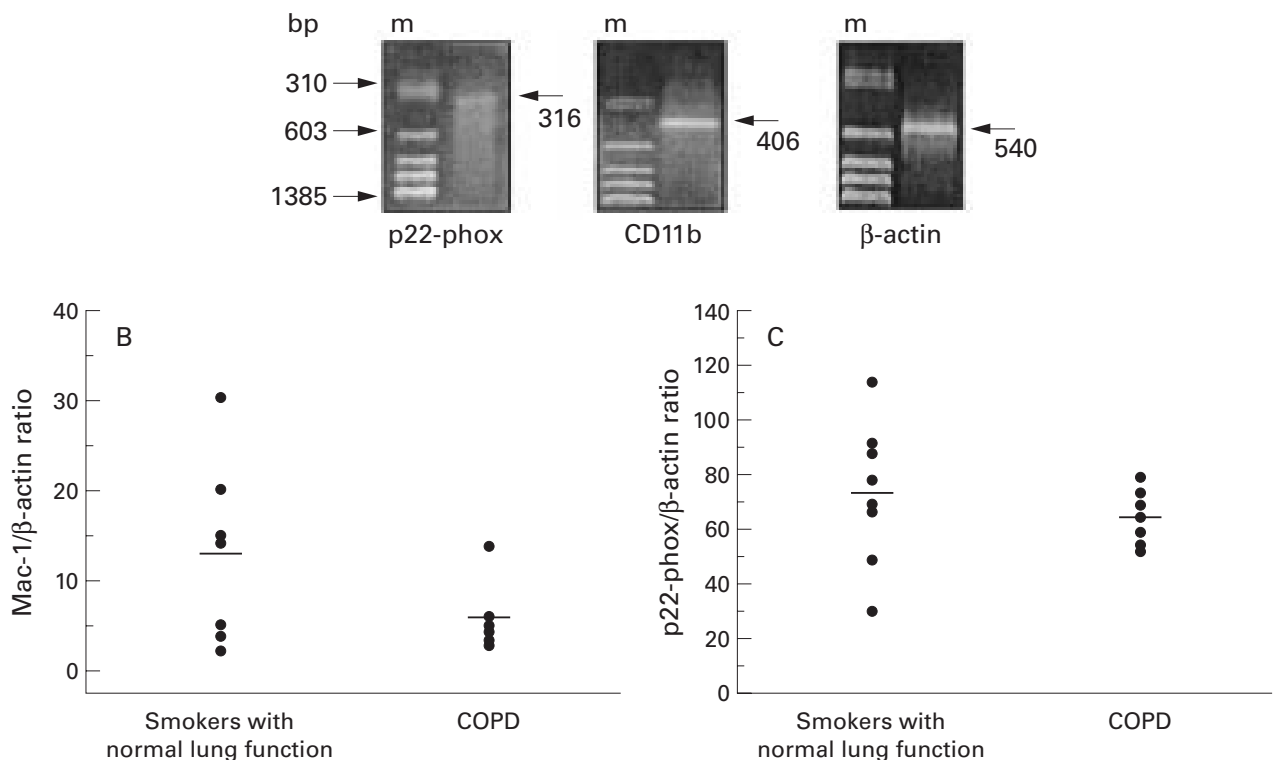

Figure 3 (A) RT-PCR product generated using specific primers for p22-phox, CD11b, and $\beta$-actin; individual and mean

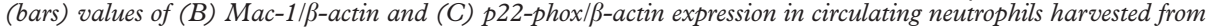
patients with COPD and long term smokers with normal lung function. Differences between groups were non-significant.

neutrophils harvested from patients with COPD and smokers with normal lung function. NADPH oxidase, the enzyme responsible for the neutrophil respiratory burst, is composed of several subunits. We chose to determine the mRNA levels of one of them (p22-phox) because p22-phox is necessary for superoxide generation ${ }^{24}{ }^{25}$ and several inflammatory stimuli such as $\mathrm{TNF} \alpha$ upregulate the expression of the p22-phox gene. ${ }^{26}$ We found that, in contrast to the significant differences observed in the respiratory burst (fig 1), p22-phox mRNA levels were similar in all the groups we studied (fig 3). The discrepancy between these results may be because NADPH oxidase activity is regulated by subunits other than $\mathrm{p} 22-p h o x$, but this is unlikely in view of the above mentioned arguments; alternatively, it is possible that post-transcriptional regulation occurs. Related to the latter, we propose that mechanisms controlling the mobilisation of secretory vesicles to the membrane in response to a given stimulus may explain our findings. ${ }^{27}$ This proposal is based on the following previous observations: (1) some NADPH oxidase subunits including p22-phox are stored in secretory vesicles when the enzyme is inactive and fuse to the membrane upon activation $^{28}$; (2) p22-phox and Mac-1 are stored in the same secretory vesicles ${ }^{28}$; (3) Mac-1 is important in the activation of the respiratory burst ${ }^{22}$; and (4) in keeping with the p22-phox mRNA data, we did not find a significant difference in Mac-1 mRNA levels (fig 3). Our observation of increased respiratory burst and surface expression of Mac-1 in patients with COPD in the absence of significant transcriptional differences could therefore be explained by enhanced mobilisation of secretory vesicles to the membrane in response to a given stimulus. This hypothesis will have to be confirmed or refuted in future studies.
In summary, this study shows that circulating neutrophils from patients with stable COPD have increased respiratory burst and express more adhesion molecules than those harvested from non-smokers (as previously described) and, importantly, than those from smokers with normal lung function. This excludes smoking as a significant cause of this abnormal neutrophil function and suggests a link to the disease itself. Future studies are required to investigate whether these abnormalities predispose to the development of COPD or are a consequence of it. In either case, our results suggest a potentially relevant pathogenic mechanism in COPD.

The authors thank M Bosch, A Noguera, F Bauzá, and C Santos for their technical collaboration during the study. They also
express their gratitude to Dr I Caragol from the Servei de express their gratitude to Dr I Caragol from the Servei de
Inmunología (Hospital Vall de Hebron, Barcelona) for her help Inmunología (Hospital Vall de Hebron, Barcelona) for her help
with the determination of the respiratory burst by flow cytometry.

Supported in part by ABEMAR and Fondo de Investigaciones Sanitarias (FIS 99/0511).

1 COPD Guidelines Group of the Standards of Care Committee of the BTS. BTS guidelines for the management of chronic obstructive pulmonary disease. Thorax 1997;52(Suppl 5):S1-28.

2 Fletcher C, Peto R. The natural history of chronic airflow obstruction. BMF 1977;1:1645-8.

3 Barnes PJ. Chronic obstructive pulmonary disease. $N$ Engl f Med 2000;343:269-80.

4 Saetta M, Turato G, Facchini FM, et al. Inflammatory cells in the bronchial glands of smokers with chronic bronchitis. Am $\mathcal{F}$ Respir Crit Care Med 1997;156:1633-9.

5 Maestrelli P, Saetta M, Di Stefano A, et al. Comparison of leukocyte counts in sputum, bronchial biopsies, and bronchoalveolar lavage. Am f Respir Crit Care Med 1995;152:1926-131.

6 Burnett D, Hill SL, Chamba A, et al. Neutrophils from subjects with chronic obstructive lung disease show enhanced chemotaxis and extracellular proteolysis. Lancet 1987;ii: 1043-6.

7 Noguera A, Busquets X, Sauleda J, et al. Expression of adhesion molecules and $G$ proteins in circulatig neutrophils in chronic obstructive pulmonary disease. $A m \mathcal{F}$ trophils in chronic obstructive pulmonar

Respir Crit Care Med 1998;158:1664-8.
8 MacNee W, Wiggs B, Belzberg AS, et al. The effect of cigarette smoking on neutrophil kinetics in human lungs. $N$ Engl f Med 1989;321:924-8. 
9 Ludwig RW, Hoidal JR. Alterations in leukocyte oxidative Ludwig RW, Hoidal JR. Alterations in leukocyte oxidative metabolism in

10 American Thoracic Society. Official statement: standardization of spirometry. 1994 update. Am $\mathcal{F}$ Respir Crit Care Med 1995;152:1107-36.

11 Roca J, Sanchis J, Agustí-Vidal A, et al. Spirometric reference values for a Mediterranean population. Bull Eur Physiopathol Respir 1986;22:217-24.

12 Emmendörffer A, Hecht M, Lohmann Matthes ML, et al. A fast and easy method to determine the production of reactive oxygen intermediates by human and murine phagocytes using dihydrorhodamine 123. F Immunol Methods 1990;131:269-75.

13 Chomczynski P, Sacchi N. Single-step method of RNA isolation by acid guanidinium thiocyanate-phenol-chloroform extraction. Anal Biochem 1987;162:156-9.

14 Zambello R, Facco M, Trentin L, et al. Interleukin-15 triggers the proliferation and cytotoxicity of granular lymphocytes in patients with lymphoproliferative disease of phocytes in patients with lymphoproliferative

15 Watanabe K, Blew B, Scherer M, et al. CD11b mRNA expression in neutrophils isolated from peripheral blood and gingival crevicular fluid. F Clin Periodontol 1997;24 814-22.

16 Jones SA, Wood JD, Coffey MJ, et al. The functional expression of p47-phox and p67-phox may contribute to the generation of superoxide by an NADPH oxidase-like system in human fibroblasts. FEBS Lett 1994;355:178-82.

17 Kishimoto TK, Jutila MA, Butcher EC. Identification of a human peripheral lymph node homing receptor: a rapidly down-regulated adhesion molecule. Proc Natl Acad Sci USA 1990;87:2244-8.

18 Renkema TEJ, Postma DS, Noordhoek JA, et al. Influence of in vivo prednisolone on increased in vitro $\mathrm{O}_{2}^{-}$generation by neutrophils in emphysema. Eur F Respir Dis 1993;6:905 .

19 Rahman I, Morrison D, Donaldson K, et al. Systemic oxidative stress in asthma, COPD, and smokers. Am $\mathcal{F}$ Respir Crit tive stress in asthma, COPD, and
Care Med 1996;154:1055-60.
20 Ming-jie Zhou, Brown EJ. CR3 (Mac-1, $\alpha \beta_{2}$, CD11b/ CD18) and FcgRIII cooperate in generation of a neutrophil respiratory burst: requirement for FcgRII and tyrosine phosphorylation. $\mathcal{F}$ Cell Biol 1994;125:1407-16.

21 Lowell CA, Fumagalli L, Berton G. Deficiency of Src family kinases p59/61 hck and p58c-fgr results in defective adhesion-dependent neutrophil functions. F Cell Biol 1996; 133:895-910

22 Liles WC, Ledbetter JA, Waltersdorph AW, et al. Crosslinking of CD18 primes human neutrophils for activation of the respiratory burst in response to specific stimuli: implications for adhesion-dependent physiological responses in neutrophils. F Leukoc Biol 1995;58:690-7.

23 Minamiya Y, Motoyama S, Kitamura M, et al. The requirement of intercellular adhesion molecule- 1 for neutrophil respiratory burst in the pulmonary circulation of rats infused with endotoxin. Am $\mathcal{F}$ Respir Crit Care Med 1998;158:635-42.

24 Jones OTG. The regulation of superoxide production by the NADPH oxidase of neutrophils and other mammalian cells. BioEssays 1994;16:919-23.

25 Maly FE, Schuerer-Maly CC, Quilliam L, et al. Restitution of superoxide generation in autosomal cytochromenegative chronic granulomatous disease (A22 ${ }^{\circ}$ CGD) derived B lymphocyte cell lines by transfection with $\mathrm{p} 22^{\text {phox }}$ cDNA. F Exp Med 1993;178:2047-53.

26 Cassatella MA, Harmant L, Perussia B, et al. Tumor necrosis factor and immune interferon synergistically induce cytochrome $\mathrm{b}_{-245}$ heavy-chain gene expression and nicotinamide-adenine dinucleotide phosphate hydrogenase oxidase in human leukemic myeloid cells. $f$ Clin Invest 1989;83:1570-9.

27 Sengelov H, Kjeldsen L, Borregaard N. Control of exocytosis in early neutrophil activation. F Immunol 1993;150: 1535-43.

28 Calafat J, Kuijpers TW, Janssen H, et al. Evidence for small intracellular vesicles in human blood phagocytes containing cytochrome b558 and the adhesion molecule CD11b/ CD18. Blood 1993;81:3122-9.

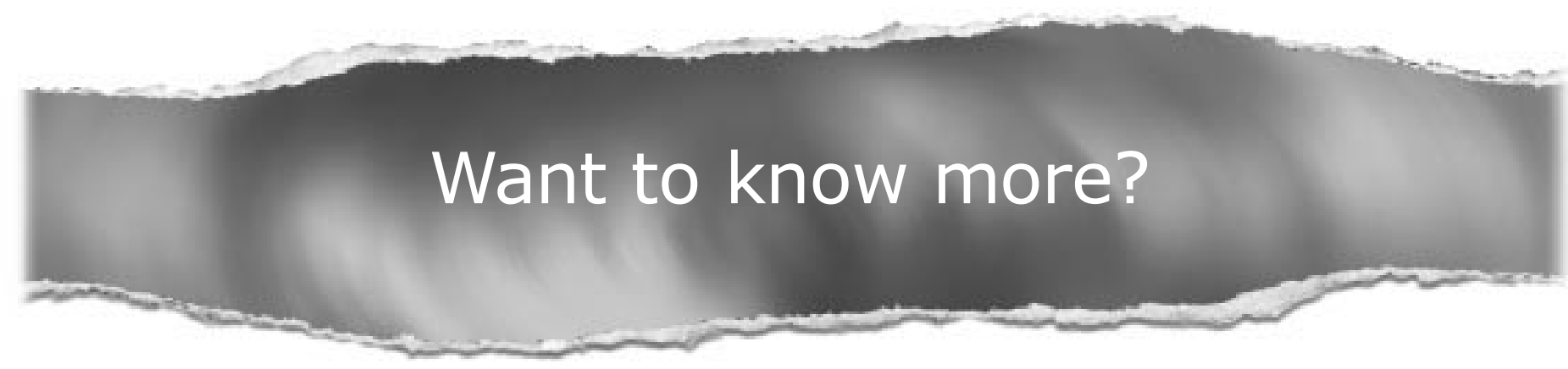

Data supplements

Limited space in printed journals means that interesting data and other material are often edited out of articles; however, limitless cyberspace means that we can include this information online.

Look out for additional tables, references, illustrations.

www.thoraxjnl.com 